\title{
Analysis on the Optimization of University Library's Organizational Structure
}

\author{
Dongqing Cai \\ Library, Huazhong university of Science and Technology, Wuhan 430074, China
}

Keywords: Organizational Structure, Optimization, University, Library, Analysis.

\begin{abstract}
This paper proposes the analysis on the optimization of university library's organizational structure. With the continuous development of library service content and management mode from traditional to modernized and digital network, librarians should not only be familiar with the collection, collation, development and utilization of paper document resources, but also the network information resources the collection, classification and integration services platform. Inspired by the state-of-the-art methodologies on the management, this paper proposes the novel paradigm for the modern college library management countermeasures.
\end{abstract}

\section{Introduction}

In the rapid development of modern high science and technology under the guidance of the rapid development, knowledge management is emerging. The innovation of library management and the establishment of knowledge innovation system have become the key to the success of library. All this is fundamentally shaken and changing the library has been accustomed to be the essential issue. As a way of life, way of thinking and management. In the process of advancing the information cluster, there are some serious problems that are worrisome. First of all, the construction of library cluster behind management thinking changes become constraints of library efficiency and decision-making level to improve the main obstacles. Second, the library from their own interests, according to the block to build their own information systems neither integration, and can later do the sharing of the resources, in fact, the formation of the "cluster separatist" situation. Third, the system lacks the overall planning and standard of information cluster construction that does not form a good atmosphere and mechanism which is beneficial to the information cluster sharing and smooth promotion, it is difficult to meet the information cluster sharing needs [1-4].

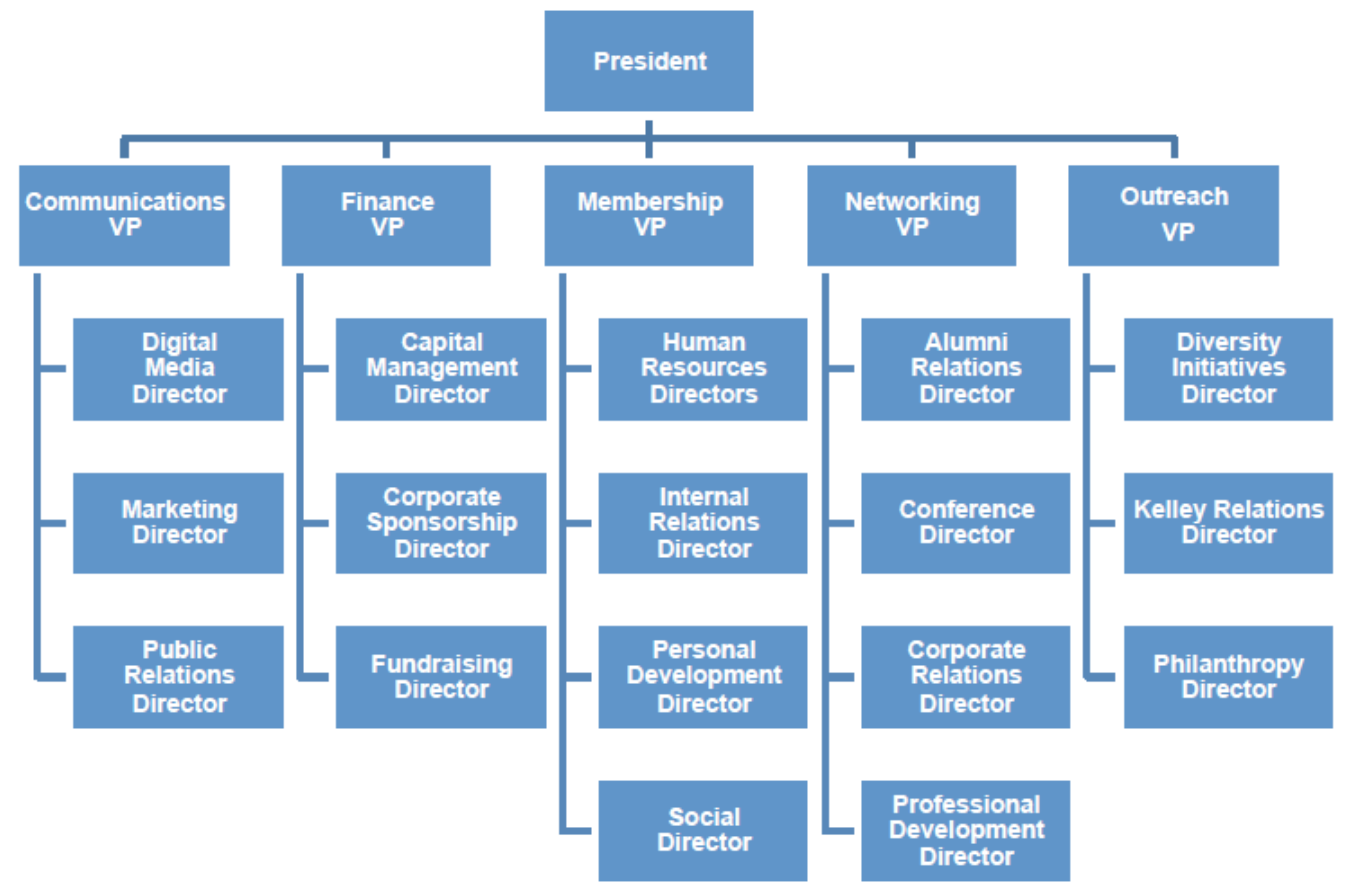

Fig. 1 Organizational Structure Management Principles 
Integrate hard management and soft management, and gradually transition to the soft management. Hard feet refer to focus on the management level, institutions, organizations, planning, control and so on economic management. Soft management refers to through knowledge innovation and knowledge drive, knowledge sharing, etc., to cultivate the overall values of the library and collective creativity. And library leaders from the past to managers, controllers, supervisor position and role, to play the role of teachers and enthusiastic friends to make the library more democracy and freedom, greater independence and creativity can really realize the value of self-value and personality. Therefore, in this paper we will primarily be focused on the following aspects.

o Library institutions according to facilitate management of literature and readers to set up, this management mode, the whole process of the information transfer by artificial segmentation, librarians to readers cannot deal directly with some of the demand need to rise and coordinate with other departments.

- The service level of the library is one of the important criteria to measure the strength of the party school and measure the level of teaching and scientific research. To this end, the library should be based on the reader service and the purpose of the construction of literature and information resources as the basis, with technical support as a general bridge to set up a new organizational structure, and strive to streamline the efficient and scientific norms.

\section{Organization of the Proposed Methodology}

\subsection{University Library Review}

University library is the modern combination of the modern informationization, socialization and so on. With the continuous development of library service content and management mode from traditional to modernized and digital network, librarians should not only be familiar with the collection, collation, development and utilization of paper document resources, but also the network information resources the collection, classification and integration services platform. The management innovation is deepens the university library reform the intrinsic demand, is the library development driving force. Along with the network, the digitized time arrival, as well as our country political system and the economic restructuring faces the depth development, a library original set of management pattern has not been able to meet the new need, but the digital library is the newly emerging things has not been possible to profit from the ready-made management system, needs to want well the survival and the development that must carries on to the traditional management idea and the ways and means develops the good and discard the bad with the choices, through the reform innovation that establishes set of brand-new management operational mechanism and meets the modern university library need to develop.

Information technology has greatly improved the human means of information communication, expand the scope of access to information, and make information communication more efficient way. All this created a favorable environment for the knowledge production and conditions, as knowledge management is an important part of the basis of material technique. It can be seen that knowledge services are services that are integrated into the user's decision-making process and are based on specialized, personalized and independent innovation services. They are based on distributed and diversified dynamic resources, systems and the integrated services. Library knowledge service is "the user is concerned and willing to spend effort and spend the cost is no longer simply to obtain the literature, but how to capture from the complex information environment and solve the problem of the information on the content, the information melting and reorganizing the corresponding knowledge or solutions, and further curing the knowledge in new products, services or management mechanisms. The connotation of knowledge management in university libraries can be summarized as follows.

- Create knowledge base, build a strong knowledge retrieval system, and also must improve knowledge environment. Librarians mainly is to create a can promote knowledge innovation and the environment. 
- In terms of university libraries, knowledge management must first create a knowledge base, and create a knowledge base to meet the party's line, principles and policies, reflecting the nature and tasks of modern colleges and universities; in the librarian's intermediary, the most appropriate knowledge at the most appropriate time to pass to the most needed faculty leaders so that they can make the best decisions.

- In founds the knowledge library in the foundation, the university library also must improve the knowledge retrieval. The knowledge retrieval is uses for to improve, the retrieval and the transmission organization knowledge, it often is through create the expert network to realize. This network is by the core expert who needs with them is composed personally and that then constructs one to have the common interest aggregate.

\subsection{Organization Structure Optimization Review}

Organizational boundaries are management scientists have been well research emphasis, but their research core is mainly the organizational boundaries of the enterprise. Because the starting point of research is different, although Adam Smith and Marx studied the boundary of the organization, but they did not form a unified definition of the organizational boundaries, however, one thing they are identical in our core views, that is: they think organizational boundaries is objective existence, any organization boundary, there is no boundaryless organization in the world. From the organization perspective, we should consider 4 aspects.

- All the departments of the organization flexibility performance within the organization has the certain tension, flexibility and adaptability have to cope with the environmental changes. Construction of multi-function, across levels of project structure, and team can yet be regarded as a kind of effective methods to enhance organizational flexibility.

- In the informationization time, the university library must use the network creation the broad information space and the quick information communication channel, as through the network establishment information actuation service mechanism, between the same profession and the different profession through altogether constructs, sharing literature resources.

- In the institutional setting, we should break through the traditional linear business process of the university library and the closed organization system with the resource structure, establish the flexible organization with the automation as the center, integrate the fixed department and cross the department to meet the needs of the users make a quick response and solve the user's actual problems and the primary challenges.

- Matrix structure can reduce the management level, and simplify the information transmission links, so that the business sector more permeable, and in order to enhance the organization's resilience and flexibility for special circumstances and temporary tasks is conducive to play the initiative and creativity of librarians but the increase in parallel organization will expand the structure, management cannot be effectively controlled.

We need to point out, no matter is the horizontal boundary or the vertical boundary so long as is the member who is in the identical boundary, they have the status and the profession homogeneity. The library profession boundary is not alone, but is the service decision by the library which department decided by library which needs to develop divides by this library all departments constitutes together.

\subsection{University Library's Organizational Structure}

From the value chain library show that a series of auxiliary for the user to create value and value creating activities to customer satisfaction as the goal of value chain is constituted of the library. The basic activities of the library include resource acquisition, resource scheduling circulation reference and user education. These links are provided by the library service is directly related to the activity, is directly for the user to create value activities; and administrative management, human resource management of the library and the information technology development, marketing and other activities constitute the auxiliary value of library.

According to the structure of the organization related research results, and to ensure that the organization has operability and sustainability, supervision, and examination mechanism must be established, namely cluster organization restraint mechanism must be established, mainly divides into 
the administrative and the technical constraints, administrative constraints, including management system, relevant laws and basic regulations, including standard, specification, technical constraints. Therefore should be additional constraints, and basic information set group of complete information cluster, to ensure that the organizational structure of vitality and creativity. Accordingly, we should separate the organizations into the following aspects.

$\circ$ Sole: On the one hand neighboring library on some development cooperation. This kind of cooperation as often is some big hall and is close to the small hall to ask the development. In order to enhance the competitive power, some small halls do not have the enough resources to provide the service that needs to draw support from other halls the strength, but this hall also needs the small hall to increase its resources and the service object.

- Regional: A regional library has its own resources and services, but also has its own conditions and advantages. If a single library is operated independently, it is inconvenient to serve the object of its own, which will cause the waste of resources and the main body of the service, and cannot form an effective competitive resource. In accordance with this type of cluster of libraries, both to play their respective professional advantages, but also the formation of the relationship between competition and cooperation. The cluster will give full play to the own characteristics, to avoid duplication of construction, to achieve dislocation development.

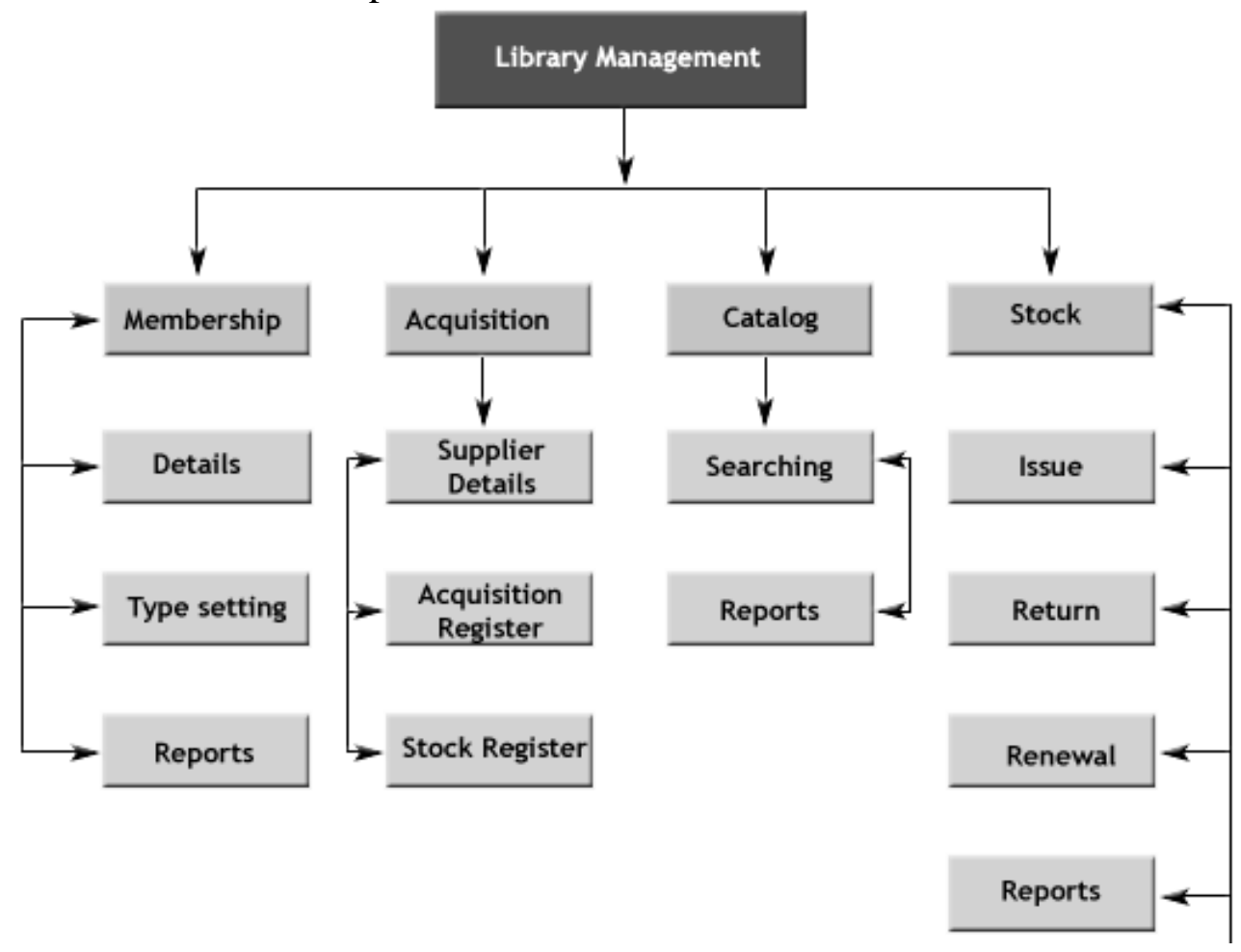

Fig. 2 University Library's Organizational Structure Optimization

\section{Conclusion}

This paper proposes the analysis on the optimization of university library's organizational structure. The management innovation is deepens the university library reform the intrinsic demand as is the library development driving force. Along with the network, the digitized time arrival, as well as our country political system and the economic restructuring faces the depth development, with a library original set of management pattern has not been able to meet the new need, but the digital library is the newly emerging things has not been possible to profit from the ready-made management system, needs to want well survival and the development that must carries on to the traditional management idea. In the future, we will apply the proposed method into more scenarios. 


\section{References}

[1] Lammers, Cornelis J., and David Hickson. Organizations Alike and Unlike (RLE: Organizations): International and Inter-Institutional Studies in the Sociology of Organizations. Vol. 17. Routledge, 2013.

[2] Carpenter, Daniel. Reputation and power: organizational image and pharmaceutical regulation at the FDA. Princeton University Press, 2014.

[3] Schore, Allan N. Affect regulation and the origin of the self: The neurobiology of emotional development. Routledge, 2015.

[4] Helfat, Constance E., and Margaret A. Peteraf. "Managerial cognitive capabilities and the microfoundations of dynamic capabilities." Strategic Management Journal 36.6 (2015): 831-850. 